\title{
Predicting Fetal Prognosis by Assessing Fetal and Maternal Blood Flow Patterns in Pregnancies with Fetal Growth Restriction
}

\author{
Natalija Vedmedovska*, Dace Rezeberga*, Uldis Teibe**, Gilbert G.G. Donders*** \\ * Department of Obstetrics and Gynecology, Riga Stradins University, Riga, Latvia \\ ** Department of Biostatistics, Riga Stradins University, Riga, Latvia \\ *** Department of Obstetrics and Gynecology of the Regional Hospital Heilig Hart Tienen, University Hospital Gasthuisberg \\ Leuven, University Hospital Citadelle, Liège, Belgium
}

\begin{abstract}
Summary
Introduction. Fetal growth restriction (FGR) is associated with prematurity and a number of complications, as well as long-term impact on metabolic or cardiac function in adults.

Aim of the Study. To study the prognostic value of staging maternal and fetal Doppler blood flow velocities in women with FGR; and evaluate prenatal characteristics as possible risk factors for severe vascular abnormalities.

Materials and methods. 70 singleton pregnancies complicated by FGR were included in prospective follow-up study. Blood flow velocities in the uterine (UtA), umbilical (AU), middle cerebral (ACM) arteries and ductus venosus (DV) were measured. FGR neonates grouped as follows: I) normal blood velocity waveforms; II) abnormal UtA velocimetry and/or presence of early diastolic "notch"; III) abnormal AU without signs of "brain sparing"; IV) abnormal AU and ACM pulsatility index (PI) and V) AU absent or reversed end diastolic flow and an abnormal DV. Prenatal risk factors and perinatal outcome were assessed in relation to these Doppler blood flow patterns and compared with Fisher exact and Pearson c2 test.

Results. There was a strong correlation between the severity of grouping and birth weight $(p<0.001)$, gestational age at delivery $(p<0.001)$, low amniotic fluid index $(p<0.001)$, low Apgar scores $(p=0.01)$ and neonatal transfer rate to NICU or hospital $(p=0.02)$. Groups IV and $V$ fetuses had the highest perinatal mortality $(p=0.01)$. Women having genital infections (RTI) had significantly worse Doppler flow profile than non-smoking women at term without RTI $(p=0.02)$.

Conclusions. Severity of blood flow redistribution correlates with fetal morbidity and mortality. Less severe vascular changes, such as abnormal AU flow without centralization, and even increased uterine artery PI alone are linked to reduced birth weight, higher likelihood of preterm birth and increased risk of morbidity. Genital infections contribute significantly to hemodynamic changes related to the FGR. Screening and preventing of STI as well as optimizing the time of delivery may improve the overall outcome of compromised fetuses.
\end{abstract}

Key words: intrauterine growth restriction, hemodynamic, outcome, infections.

\section{INTRODUCTION}

Fetal growth restriction (FGR) is defined as the inability of a fetus to maintain expected growth, with estimated fetal weight or actual birth weight below the 10th percentile for gestational age (1). Fetal growth restriction is associated with prematurity and a number of complications, such poor neural development and risk of epilepsy in childhood and long-term impact on metabolic or cardiac function in adults $(10,12.16$, $34,37)$. The FGR remains the challenge for clinicians, therefore, the different kind of fetal well-being assessment methods incorporated in obstetrics. Doppler ultrasonography has been proposed for identifying pathological growth and predicting fetal compromise $(27,44)$. The link between abnormal patterns of Doppler velocities of maternal and fetal vessels and fetal outcome was reported in a number of studies (3, $4,8,11,43)$. Researchers tried hard to understand the etiopathogenesis and the underlying mechanisms of fetal impairment occurring between the diagnosis and the moment of delivery or death (26).
Although in the literature, we could find some scarce data evaluating the effect of smoking on the umbilical blood flow indices (22) or the hemodynamic changes following steroids administration $(32,36)$, the influence of maternal characteristics, such as genital infections and smoking on blood flow pattern among FGR fetuses were not sufficiently evaluated.

\section{AIM OF THE STUDY}

To assess changes in maternal and fetal flow velocity in pregnancies complicated by intrauterine fetal growth restriction, and their correlation with perinatal outcomes on the one hand, and possible interactions of antenatal risk factors on the other.

\section{MATERIALS AND METHODS}

We conducted a prospective study from May 2007 to March 2010. Seventy consecutive women with intrauterine growth restriction of singleton fetuses, attending the ultrasound unit at Riga Maternity Hospital in Latvia, were included in the study. Growth restriction 
was defined as an estimated weight below the $10^{\text {th }}$ percentile by prenatal ultrasound. Exclusion criteria were rhesus immunization, chromosomal aberrations and morphological malformations. In an estimate to create different levels of prognostic severity, intrauterine growth restricted newborns were divided in 5 groups according to their pattern of flow. Group I consisted of fetuses with normal blood velocity waveforms; Group II of fetuses with an abnormal velocimetry of the arteria uterine (UtA) and/or presence of early diastolic "notch"; Group III of fetuses with an abnormal arteria umbilicalis $(A U)$ pulsatility index (PI); group IV of fetuses with abnormal $A U$ and low arteria cerebri media (ACM) PI and, finally, group $\mathrm{V}$, fetuses with $A U$ absent or reversed end diastolic (ARED) flow and/or an abnormal ductus venosus $(D V)$ flow. Oligohydramnios was considered in presence of amniotic fluid index less than $5 \mathrm{~cm}(24$.

The Ethics Committee of Riga Stradins University approved the study and informed consent was obtained from all patients.

Doppler studies. The patients were examined using a 2-5, 2-7 or 4-8 MHz abdominal transducer (Philips, AU 22, USA) with color Doppler and pulsed Doppler facilities. The high-pass filter was set as low as possible, at $70 \mathrm{~Hz}$. The mechanical and thermal indices were always kept below 1.9 and 1.5 .

At each session we measured blood flow velocity in UtA, $A U, M C A$ and $D V$. We applied standardized techniques $(14,19,25)$. Briefly, the UtA was identified at the apparent crossing of the uterine and external iliac arteries. Measurements were taken approximately $1 \mathrm{~cm}$ distal to the crossover point. Abnormal UtA velocimetry was considered as a mean (left and right) PI value above the $95^{\text {th }}$ percentile for gestational age (GA) based reference ranges (14) and/or presence of early diastolic "notch".

The umbilical artery recordings performed at the free-floating loop of the umbilical cord. Abnormal $A U$ velocimetry was defined as PI above the $95^{\text {th }}$ for GA based reference ranges (2).

$A C M$ was assessed in axial section of brain with the sample volume over the proximal section where $A C M$ emerges from circle Willis. Abnormal $A C M$ velocimetry was defined as PI below the $2.5^{\text {th }}$ for GA based reference ranges (9).

The ductus venosus was identified in mid-sagittal transaction as a vessel connecting the umbilical vein with inferior vena cava and exhibiting the typical aliasing of high velocities compared with the umbilical vein. Abnormal $D V$ was defined as PI above the $95^{\text {th }}$ for GA based reference ranges and/or ARED (17).

All recordings have been obtained in the absence of fetal breathing and fetal movement. The angle of insonation always was kept lower than $30^{\circ}$. Women were placed in a semi-recumbent position.

When more than one Doppler study was performed in the same fetus, the last Doppler study preceding delivery was used for analysis.

Delivery. The decision on the best mode of delivery was based on the gestation, fetal condition and cervical status as determined by the managing obstetrician. Information regarding birth weight, gestational age at delivery, mode of delivery, and length of hospital stay was obtained from standardized medical records.

Neonates. 5-minute Apgar score below 7, neonatal health, admission to neonatal intensive care unit, transfer to pediatric hospital for further treatment, and neonatal death were assessed.

Statistical analysis. Data were analyzed with SPSS statistical software version 18. Parametric statistics are presented as mean and standard deviation. The differences in the proportion of adverse outcomes in each Doppler groups was compared by the Fisher's exact test, Pearson $c^{2}$ test, chi-square for trend or for multiple non-Gaussian samples Krsukal Wallis, p value of $<0.05$ was considered statistically significant.

\section{RESULTS}

Demographic and clinical characteristics of the study population were described elsewhere (40-41). Doppler waveforms were recorded within seven days of delivery (ranges $2 \mathrm{~h}-7$ days). The outcome variables were compared with the results of the Doppler examinations. The mean gestational age at delivery was higher in Group I (38.2 \pm 3.3$)$ compared with other groups (37.2 \pm $4.2 ; 36.2 \pm 2.6 ; 36.4 \pm 3.6$ and $31.1 \pm 3.1$, respectively, $c^{2}$ $=60.33 ; \mathrm{p}<0.001)$.

The Pearson correlation test showed an overall significant decrease in birth weights among the groups $(p<0.001)$. The mean birth weight in the first group was $2530 \pm 473 \mathrm{~g}$ compared to the $1229403 \mathrm{~g}$ in Group V (Table N 1). Placental resistance and low ACM PI (Group IV) was associated with reduced birthweight.

Adverse perinatal outcome was lowest when Doppler study profile was normal and highest when Doppler examination on both maternal and fetal side was abnormal (Table N 1). Neonatal morbidity was $67 \%$ for Group III neonates. This was largely attributable to prematurity (nine cases) and RDS (nine cases) see Table N 1 .

Oligohydramnios was associated with increasing severity of Doppler vascular changes (Normal ®Abnl UtA ${ }^{\circledR}$ Abnl $A U$ ( Abnl $A U$ and $A C M$ ®and $A U$ ARED and Abnl $D V, \mathrm{p}<0.001)$. Unexpectedly, delivery by cesarean section, pre-eclampsia and the incidence of placental abruption were all observed more often in the group with increased umbilical artery PI without "brain-sparing" than in other groups (e.g. in Group III) $(\mathrm{p}=0.007 ; \mathrm{p}=0.25 ; \mathrm{p}=0.62$, respectively). In all cases of placental abruption the presence of a "notch" was demonstrated in the UtA Doppler flow patterns.

Absent or reverse diastolic flow of $A U$, abnormal $A C M$ and $D V$ PI showed a direct correlation with 5-minute Apgar scores below 7, transfer to NICU, transfer to pediatric hospital for further treatment and intranatal mortality $(\mathrm{p}=0.01 ; \mathrm{p}=0.01 ; \mathrm{p}=0.02 ; \mathrm{p}=0.03$, respectively, Table N 1).

Perinatal mortality occurred only in Group IV (2/12, $16.7 \%)$ and in Group V $(2 / 8,25 \%)$. Three of four deaths occurred during delivery, one due to placental 
abruption, and three due to severe pre-eclampsia. Three of eight fetuses of group $\mathrm{V}$ were born prematurely, had respiratory distress syndrome and developed severe intraventricular hemorrhage Grade III or IV. The mean length of stay of FGR infants in the NICU was $6( \pm 1.6)$ days, statistically different amongst groups $(\mathrm{p}=0.016)$.

Thirteen women from FGR group were smokers and in 10 women reproductive tract infections $(C$. trachomatis $\mathrm{n}=4 ; \mathrm{BV} \mathrm{n}=6$ ) were confirmed during pregnancy. Women with genital infections $(p=0.02)$ had four times more frequent Doppler flow abnormalities compared to women without any other preventable risk factor (genital infections, smoking), $\mathrm{p}=0.018$ (Table $N$ l). Smoking women with FGR have no different Doppler profile compared with normal women $(\mathrm{p}=0.09)$.

\section{DISCUSSION}

In the human fetuses, placental and fetal compromise are often associated with augmented PI of the umbilical artery (39), and redistribution of the blood flow within the fetal body in order to benefit the cerebral circulation $(18,20,30)$. Different staging systems were proposed in order to allow timely delivery of fetuses $(13,28)$. In the present study, we report on the relation between ultrasonographic and clinical parameters of these high-risk pregnancies. Unlike in the study of Mari et al. (27) we also included the maternal uterine artery flow studies in our analysis and found not only that advancing hemodynamic changes are associated with increased perinatal mortality but also that abnormal UtA flow in itself was associated with adverse neonatal outcome in surviving babies (low 5-minute Apgar, increased neonatal morbidity, as evidenced by increased transfer to NICU and pediatric hospitals). Therefore, we support Gosh et al.'s (13) suggestion that the uterine artery flow studies should be included in the routine Doppler evaluation of women presenting with impaired fetal growth.

Furthermore, before delivery, the presence of a "notch" was demonstrated in the UtA flow on Doppler examinations in all five cases of placental abruption. As these events all occurred while the patients were hospitalized, four of the five neonates managed to survive.

In this study we hypothesized that fetal prognosis can be assessed by classifying Doppler abnormalities according to the severity in five different groups: from normal flow (Group I), to maternal flow abnormalities only (Group II), fetal uncomplicated flow abnormalities (Group III), abnormalities with brain "sparing effects" (Group IV) and finally to the flow indicating decompensation of the fetal circulation (Group V). We could clearly demonstrate a prognostic link between these groups and both fetal mortality and neonatal morbidity. Furthermore, we demonstrated that the most severe hemodynamic changes (Groups III-V) in FGR fetuses are achieved early in gestation, i.e. at the end of second or early in the third trimester. Inevitably, fetuses from Groups III-V were delivered earlier than fetuses of Groups II or I. Other studies have shown that placental compromise is indeed more pronounced if circulatory deprivation occurs before 32 weeks of gestation, and that late-onset cases have minimal placental involvement and more subtle Doppler findings $(5,23)$.

Unexpectedly, FGR women of III Group (abnormal $A U$ without centralization) most often were delivered by cesarean section, which was even a higher rate than the compromised fetuses of Groups IV and V. We presume this might be due to the lack of specific clinical guidelines for the FGR management in Latvia. The prognosis for fetuses in Group III was actually good, with no perinatal deaths in this group. As these babies could have benefitted from delayed delivery as long as the elevated umbilical artery PI is not associated with signs of blood flow redistribution, such as in Groups IV and $\mathrm{V}$, we would recommend conservative management for those fetuses, albeit under close supervision.

In a previous study, our group reported that smoking in association with fetal growth restriction showed more often intervillous hematomas and villous infarction in the placenta (42). In the present study, however, the pattern of Doppler velocities was similar between smoking and non-smoking women with FGR pregnancies. These findings seem to confirm the hypothesis that placental underperfusion in smokers might be periodic rather than continuous (31).

Compared to non-smoking controls delivering at term, we found more genital infections associated with more severe flow abnormalities. Therefore, besides to the known increased risk of preterm birth $(15,29,33)$, genital infections like $\mathrm{BV}$ are not only linked to the increased likelihood of FGR (41), but also constitute an increased risk for placental abruption as shown by impaired Doppler pattern in the uterine arteries. In former studies we have demonstrated that also aerobic genital infections in the beginning of pregnancy were associated with an increased risk for chorioamnionitis, but also funisitis and fetal infection (35). The pathway of intrauterine ascending infections from abnormal vaginal flora, leading to increased intraamniotic proinflammatory cytokines, periventricular leucomalacia and cerebral palsy, was clearly documented by Yoon and coworkers (45). Infants born after the diagnosis of absent or reversed end-diastolic flow in umbilical artery (Group V) are particularly at risk of central nervous system complications and need more frequent parenteral feeding (21). Several abnormal flora types are involved in the causation of such pregnancy complications (7), and therefore, early screening and timely treatment with adequate antibiotics, like clindamycin, might lead to improved pregnancy outcomes $(6,38)$. However, specific associations between the presence of genital infections and FGR have been documented only sporadically, perhaps because the emphasis of the previous studies was mostly on the prevention of preterm birth and not FGR. We hope our new data inspire researchers to perform more studies on the link between genital infections and FGR, and try to provide evidence that can help to install preventive actions to dampen the severe damage of these small babies by early screening and treatment. 


\section{CONCLUSIONS}

Severity of blood flow redistribution correlates with fetal morbidity and mortality. Less severe vascular changes, such as abnormal $A U$ flow without centralization and even increased uterine artery PI alone are linked with reduced birth weight, higher likelihood of preterm birth and increased risk of morbidity. Genital infections contribute significantly to hemodynamic changes in FGR. Screening and preventing of RTI, as well as optimizing the time of delivery may improve the overall outcome of compromised fetuses.

\section{Conflict of interest: None}

\section{REFERENCES}

1. ACOG Practice Bulletin. Intrauterine Growth Restriction. No.12 // Int J Gynecol Obstet, 2001; 72:85 - 96

2. Ascharya G, Wilsgaard T, Berntsen, GKR, Maltau JM, Kiserud T. Reference ranges for serial measurements of umbilical artery Doppler indices in the second half of pregnancy // Am J Obstet Gynecol, 2005; 192:937 - 944

3. Baschat AA, Cosmi E, Bilardo CM, Wolf H, Berg C, Rigano S, Germer U, Moyano D, Turan S, Hartung J, Bhide A, Müller T, Bower S, Nicolaides KH, Thilaganathan B, Gembruch U, Ferrazzi E, Hecher K, Galan HL, Harman CR. Predictors of neonatal outcome in early-onset placental dysfunction // Obstet Gynecol, 2007; 109: 253 - 261

4. Cheema R, Dubiel M, Breborowicz G, Gudmundsson S. Fetal cerebral venous Doppler velocimetry in normal and high-risk pregnancy // Ultrasound Obstet Gynecol, 2004; 24: 147 - 53

5. Crispi F, Domínguez C, Llurba E, Martín-Gallán P, Cabero L, Gratacós E. Placental angiogenic growth factors and uterine artery Doppler findings for characterization of different subsets in preeclampsia and in isolated intrauterine growth restriction // Am J Obstet Gynecol, 2006; 195:201 - 7

6. Donders GG. Treatment of sexually transmitted diseases in pregnant women // Drugs, 2000; 59: $477-85$

7. Donders GG, Van Calsteren K, Reybrouck R, Van den Bosch T, Riphagen I, Van Lierde S. Predictive value for preterm birth of abnormal vaginal flora, bacterial vaginosis and aerobic vaginitis during the first trimester of pregnancy // BJOG, 2009; 116:1315-24

8. Dubiel M, Breborowicz GH, Gudmundsson S. Evaluation of fetal circulation redistribution in pregnancies with absent or reversed diastolic flow in the umbilical artery // Early Hum Dev, 2003; $71: 149-56$
9. Ebbing C, Rasmussen S, Godfrey KM, Kiserud T. Fetal celiac and splenic artery flow velocities and pulsatility index: longitudinal reference ranges and evidence for vasodilatation at a low ortocaval pressure gradient. Ultrasound Obstet Gynecol, 2008; 32: $663-72$

10. Evensen KA, Steinshamn S, Tjønna AE, Stølen T, Høydal MA, Wisløff U, Brubakk AM, Vik T. Effects of preterm birth and fetal growth retardation on cardiovascular risk factors in young adulthood // Early Hum Dev, 2009; 85:239 - 45

11. Ferrazzi E, Bozzo M, Rigano S, Belloti M, Morabito S, Pardi G. et al. Temporal sequence of abnormal Doppler changes in the periferal and central circulatory systems of severely growth restricted fetus // Ultrasound Obstet Gynecol, 2002; 19:140 6

12. Fortes Filho JB, Valiatti FB, Eckert GU, Costa MC, Silveira RC, Procianoy RS.) Is being small for gestational age a risk factor for retinopathy of prematurity? A study with 345 very low birth weight preterm infants // J Pediatr, 2009; 85:48 54

13. Ghosh GS, Gudmundsson S. Uterine and umbilical arteries Doppler are comparable in predicting perinatal outcome of growth-restricted fetuses // BJOG, 2009; 116:424 - 30

14. Gomez O, Figueras F, Fernandez S, Bennasar M, Martinez JM, Puerto B, Gratacos E. Reference ranges for uterine artery mean pulsatility index at 11-41 weeks of gestation // Ultrasound Obstet Gynecol, 2008; 32:128 - 132

15. Guaschino S, De Seta F, Piccoli M, Maso G, Alberico S. Aetiology of preterm labour: bacterial vaginosis // BJOG, 2006; 113: Suppl3, 46 - 51

16. Henriksen T. Foetal nutrition, foetal growth restriction and health later in life // Acta Pediatr Suppl, 1999; 88:4-8

17. Kessler J, Rasmussen S, Hanson M, Kiserud T. Longitudinal reference ranges for ductus venosus flow velocities and waveform indices // Ultrasound Obstet Gynecol, 2006; 28:890 - 8

18. Kilavuz $\mathrm{O}$, Vetter $\mathrm{K}$. Is the liver of the fetal the $4^{\text {th }}$ preferential organ for arterial blood supply besides brain, heart, and adrenal glands? // J Perinat Med, 1999; 27:103-6

19. Kiserud T, Eiknes SH, Blaas HGK, Hellevik LR. Ultrasonographic velocimetryof the fetal ductus venosus // Lancet, 1991; 338:1412 - 1414

20. Kiserud T, Kessler J, Ebbing C, Rasmussen S.). Ductus venosus shunting in growth-restricted fetuses and the effect of umbilical circulatory compromise // Ultrasound Obstet Gynecol, 2006; 
28:143- 149

21. Kornacki J, Kornacka A, Rajewski M, Goździewicz T, Skrzypczak J, Szczapa J. Do abnormal results of Doppler examinations in fetuses with growth restriction increase the frequency of postnatal complications of the central nervous system and gastrointestinal tract? // Ginekol Pol, 2009; 80: $839-44$

22. Kudielka I, Raimann H, Schurz B, Schatten C, Eppel W, Reinold E Umbilical blood flow indices in smoking women // Z Geburtshilfe Perinatol, 1992; 196:213-6

23. Llurba E, Carreras E, Gratacós E, Juan M, Astor J, Vives A, Hermosilla E, Calero I, Millán P, GarcíaValdecasas B, Cabero L. Maternal history and uterine artery Doppler in the assessment of risk for development of early- and late-onset preeclampsia and intrauterine growth restriction // Obstet Gynecol Int, 2009; 275613

24. Manning FA, Platt LD, Sipos L. Antepartum fetal evaluation: development of a fetal biophysical profile // Am J Obstet Gynecol, 1980; 136:787 - 95

25. Mari G, Abuhamad AZ, Cosmi E, Segata M, Altaye $M$ and Akiyama M. Middle cerebral artery peak systolic velocity-technique and variability // J Ultrasound Med, 2005; 24:425 - 430

26. Mari G, Deter RL, Hanif F, Treadweel M, Kruger M. Sequence of cardiovascular changes occuring in severeIUGR fetuses: Part II // Ultrasound Obstet Gynecol, 2006; 28:390

27. Mari G, Hanif F, Drennan K, Kruger M. Staging of intrauterine growth-restricted fetuses // J Ultrasound Med, 2007; 26:1469-77

28. Mari G, Picconi J. Doppler vascular changes in intrauterine growth restriction // Semin Perinatol, 2008; 32:182 - 189

29. Museva A, Shopova E, Dimitrov A, Nikolov A. Participation of the genital mycoplasmas: Ureoplasma urealyticum and Mycoplasma hominis in the processes of preterm birth // Akush Ginecol (Sofia), 2007; 46 Suppl 4:12-5

30. Natanielsz PW, Hanson MA. The fetal dilemma: spare the brain and spoil the liver // J PhysiolLondon, 2003; 548:33

31. Newnham J, Patterson L, James I, Reid SE. Effect of maternal smoking on ultrasonic measurements of fetal growth and on Doppler flow velocity waveforms // Early Hum Dev, 1990; 24:23 - 26

32. Nozaki AM, Franchisco RPV, Fonseca ESVB, Miyadahira S, Zugaib M. Fetal hemodynamic changes following maternal betamethasone administration in pregnancies with fetal growth restriction and absent end diastolic flow in the umbilical artery // Acta Obstet Gynecol, 2009; $88: 350-354$

33. Pretorius C, Jagatt A, Lamont RF. The relationship between periodontal disease, bacterial vaginosis, and preterm birth // J Perinat Med, 2007, 35:93 - 9

34. Procianoy RS, Koch MS, Silveira RC. Neurodevelopmental outcome of appropriate and small for gestational age very low birth weight infants // J Child Neurol, 2009; 24: 788 - 94

35. Rezeberga D, Lazdane G, Kroica J, Sokolova L, Donders GGG. Placental histological inflammation and reproductive tract infections in a low risk pregnant population in Latvia // Acta Obstet Gynecol Scand, 2008; 87:360 - 5

36. Simchen MJ, Alkazaleh F, Adamson SL, Windrim $\mathrm{R}$, Telford J, Beyene J. et al. The fetal cardiovascular response to antenatal steroids in severe early-onset intrauterine growth restriction // Am J Obstet Gynecol, 2004; 190:296 - 304

37. Sun Y, Vestergaard M, Pedersen CB, Christensen J, Basso O, Olsen J. Gestational age, birth weight, intrauterine growth, and the risk of epilepsy. Am J Epidemiol, 2008; 167:262 - 70

38. Swadpanich U, Lumbiganon P, Prasertcharoensook W, Laopaiboon M. Antenatal lower genital tract infection screening and treatment programs for preventing preterm delivery // Cochrane Database Syst Rev, 2008; 16:CD006178

39. Trudinger BJ, Giles WB, Cook CM, Bombardieri J, Collins L. Fetal umbilical artery flow velocity waveforms and placental resistance-clinical significance // BJOG, 1985; 92:23 - 30

40. Vedmedovska N, Rezeberga D, Teibe U, Donders GGG, Polukarova S. Fetal Growth Restriction in Latvia // IJOG, 2010; doi: 10.1016/j.ijgo. nt J Gynaecol Obstet. 2010 Nov; $111(2)$ :185-6.

41. Vedmedovska N, Rezeberga D, Teibe U, Donders GGG. Preventable maternal risk factors and association of genital infection with Fetal Growth Restriction // Gynecol Obstet Invest, 2010; 70: 219-226

42. Vedmedovska N, Melderis I, Rezeberga D, Teibe U, Donders GGG. Placental pathology in foetal growth restriction and smoking // Eur J Obstet Gynecol Reprod Biol. 2010 Dec 21. [Epub ahead of print], in press

43. Verburg BO, Jaddoe VW, Wladimiroff JW, Hofman A, Witteman JC and Steegers E A. Fetal hemodynamic adaptive changes related to intrauterine growth // Circulation, 2008; 117:649-659

44. Zelop CM, Richardson, Heffner U. Outcomes of severely abnormal umbilical artery Doppler velocimetryinstructurallynormalsingletonfetuses // Obstet Gynecol, 1996; 87:434 - 438

45. Yoon BH, Romero R, Kim CJ, Koo JN, Choe G, Syn HC, Chi JG. High expression of tumor necrosis factor-alpha and interleukin-6 in periventricular leucomalacia // Am J Obstet Gynecol, 1997; $177: 406-11$ 
Table 1. Characteristics of FGR groups according to Doppler profile, data are given as numbers and SD, percentage in parenthesis

\begin{tabular}{|c|c|c|c|c|c|c|}
\hline & $\begin{array}{c}\text { Group I } \\
(n=18)\end{array}$ & $\begin{array}{c}\text { Group II } \\
(\mathrm{n}=14)\end{array}$ & $\begin{array}{c}\text { GroupIII } \\
(n=18)\end{array}$ & $\begin{array}{c}\text { GroupIV } \\
(n=12)\end{array}$ & $\begin{array}{c}\text { GroupV } \\
(\mathrm{n}=8)\end{array}$ & $P$ value \\
\hline \multicolumn{7}{|c|}{ - Preventable risk factors } \\
\hline $\mathrm{Nl} *(\mathrm{n})$ & 12 & 3 & 7 & 4 & 0 & Ref \\
\hline Smoking $(\mathrm{n})$ & 3 & 1 & 2 & 2 & 3 & 0.09 \\
\hline STI (n) & 1 & 4 & 1 & 2 & 2 & 0.018 \\
\hline \multicolumn{7}{|c|}{ - Acute pregnancy complications } \\
\hline Preeclampsia & $1(6)$ & $1(7)$ & $4(22)$ & 0 & $1(13)$ & 0.25 \\
\hline Placenta abruption & $0(0)$ & $1(7)$ & $3(16.6)$ & $1(8)$ & 0 & 0.62 \\
\hline C-section & $6(33)$ & $9(64)$ & $17(94)$ & $7(58)$ & $6(75)$ & 0.007 \\
\hline \multicolumn{7}{|c|}{ - Perinatal outcome } \\
\hline Birth weight & $2530 \pm 473$ & $2270 \pm 364$ & $1945 \pm 111$ & $1746 \pm 516$ & $1229 \pm 403$ & 0.001 \\
\hline Gestational weeks & $38.2 \pm 3.3$ & $37.2 \pm 4.2$ & $36.2 \pm 2.6$ & $36.4 \pm 3.6$ & $31.1 \pm 3.1$ & 0.001 \\
\hline Amniotic fluid index $<5$ & $2(6)$ & $2(14)$ & $4(22)$ & $3(25)$ & $3(38 \%)$ & 0.001 \\
\hline Perinatal mortality & $0(0)$ & $0(0)$ & $0(0)$ & $2(16)$ & $2(25)$ & 0.01 \\
\hline 5-min Apgar score $<7$ & $0(0)$ & $1(7)$ & $1(6)$ & $2(17)$ & $5(63)$ & 0.01 \\
\hline Neonatal morbidity & $1(6)$ & $4(29)$ & $12(67)$ & $3(10)$ & $6(100)$ & 0.0004 \\
\hline Transfer to NICU & $0(0)$ & $1(7)$ & $5(28)$ & $1(10)$ & $5(83)$ & 0.01 \\
\hline $\begin{array}{l}\text { Transfer to pediatric } \\
\text { hospital }\end{array}$ & $1(6)$ & $4(29)$ & $8(44)$ & $4(40)$ & $6(100)$ & 0.02 \\
\hline
\end{tabular}

*non smoking, no genital infection

$\mu$ : P value versus reference group of women without preventable risk factors only (non smoking, no STI)

\section{Address:}

Natalija Vedmedovska

Department of Obstetrics and Gynecology,

Riga Stradins University,

Dzirciema street 16, Riga LV-1013, Latvia

E-mail address: natalyved@apollo.lv 